\title{
A MATEMÁTICA NO ENSINO DE ENGENHARIA
}

\author{
G. L. FIRMINO, A.M. O. SIQUEIRA ${ }^{1}$ \\ ${ }^{1}$ Universidade Federal de Viçosa - Departamento de Química - Programa de Pós-Graduação \\ em Engenharia Química - Viçosa - MG \\ E-mail: antonio.siqueira@ufv.br
}

RESUMO: A dificuldade no aprendizado em Matemática tem sido objeto de pesquisas, encontros, palestras, objetivando descobrir as origens dos problemas no ensino/aprendizagem, este trabalho teve por objetivo identificar as principais dificuldades enfrentadas pelos alunos dos cursos de Engenharia quando da resolução de problemas, do ponto de vista dos recursos de matemática e especificamente, investigar os conceitos matemáticos mínimos para a satisfatória resolução de problemas em disciplina-meio do cursos de Engenharia. Os levantamentos foram realizados por meio de entrevistas e coleta de dados, por meio eletrônico. Nota-se que as dificuldades em Matemática encontradas pelos alunos ao ingressarem no Ensino Superior, tornam-se cada vez mais frequentes e diante dos problemas na aprendizagem do Cálculo e disciplinas afins, os usos de TIC's podem contribuir para a melhoria do processo ensino-aprendizagem. $O$ uso de recursos tecnológicos quando utilizados de maneira correta se tornam auxiliares, facilitando a aprendizagem dos conteúdos matemáticos, motivando os alunos a estruturar seu próprio conhecimento. A metodologia usada pelos professores também tem interferido na aprendizagem dos alunos, "pois muitos deles sentem dificuldades ao se depararem com uma linguagem muito direta e com um ritmo acelerado para cumprir a carga horária”, conforme destacam diversos pesquisadores da área. Sendo assim, as metodologias tradicionais adotadas por muitos professores contribui para o fracasso de muitos alunos, por não dar atenção às dificuldades dos mesmos, causando insegurança e angústia, pois eles encontram um alto grau de abstração nos conteúdos. Nesse sentido, recomenda-se a associação de novas tecnologias educacionais, como o uso de TIC's e da Web 2.0, bem como um processo de reflexão por parte dos professores sobre a sua prática docente.

PALAVRAS-CHAVE: Ensino-aprendizagem; Matemática; Cálculo, Ensino de Engenharia.

\section{INTRODUÇÃO}

A dificuldade no aprendizado em Matemática tem sido objeto de pesquisas, encontros, palestras, objetivando descobrir as origens dos problemas no ensino/aprendizagem, cabendose destacar os diversos trabalhos apresentados no âmbito do Congresso Brasileiro de 
Educação em Engenharia - COBENGE (PILOTTI, CUNHA e PARMEGIANI, 2014; QUARTIERI, BORRAGINI E DICK, 2012 e BARROS e MELONI, 2006).

Segundo Almeida (2006) "algumas questões são recorrentes nestes debates e pesquisas tais como: A deficiência está no próprio sistema de ensino? Os professores não estão conseguindo lidar com o processo? Os alunos não estariam desmotivados? O que leva o aluno a não conseguir aprender Matemática e/ou outras disciplinas?". Muitas outras questões são levantadas para tentar buscar uma resposta e prováveis soluções para os problemas atuais na educação.

Dentro desta ótica, considerando que a Matemática é ferramenta imprescindível para a educação e formação do profissional de engenharia e que o principal papel da matemática é prover os alunos "de subsídios que os permita interpretar os dados, analisar os modelos propostos, de forma que possam melhor representar a realidade, adquirindo ferramentas que lhes possibilite a resolução de problemas" (PINHEIRO e MORETTI, 2003), este trabalho, que resulta do projeto de pesquisa em ensino "Resolução de problemas: a matemática no ensino de engenharia" propõe a investigação dos conceitos matemáticos mínimos para a satisfatória resolução de problemas em disciplinas-meio do cursos de Engenharia na universidade, bem como identificar as principais dificuldades enfrentadas pelos alunos de engenharia quando da resolução de problemas.

\section{FUNDAMENTAÇÃO TEÓRICA}

Trevisan e Mendes (2013) e diversos outros pesquisadores esclarecem que o paradigma da Educação Superior "ainda se encontra baseado em modelos tradicionais de ensino, nos quais o professor apresenta os conteúdos aos estudantes e dá informações ou instruções de como resolver exercícios-tipo por meio de aulas expositivas. Segundo estes mesmos autores, "as competências desenvolvidas pelos alunos restringem-se às habilidades de reprodução e memorização, muitas desaparecendo logo após a realização das avaliações."

Como destacam Trevisan e Mendes (2013), "nas aulas das disciplinas da área de Matemática, a prática pedagógica de muitos dos professores envolvidos com os diferentes .. é comum: os professores usam o mesmo plano de ensino para disciplinas de mesma ementa em cursos diferentes, ou seja, mesma distribuição do programa, mesma metodologia, mesmos livros, mesmos instrumentos de avaliação, sem levar em consideração as idiossincrasias de cada curso."

Nos cursos de Engenharia este fato é uma recorrência e observa-se, principalmente, que a Educação Matemática (relacionada principalmente as disciplinas do ciclo básico, como Cálculo, Geometria Analítica e Álgebra Linear), mesmo com expressiva pesquisa e reestruturações curriculares ao longos dos anos, e empenho dos docentes, não propicia ao estudante, em geral, a suficiente ou adequada habilidade para interpretar e solucionar problemas, por meio de recursos matemáticos, como também lembram Moraes e Valente (2016).

Observa-se que as disciplinas do ciclo básico da área de matemática e das quais as disciplinas supra mencionadas têm como base, não tem garantido o "conhecimento" e a importância necessária por parte dos estudantes. Embora, de um modo geral, estes mesmos estudantes, tenham ou possam ter obtido, notas relativamente altas nas referidas disciplinas.

Muitas vezes, surge o seguinte questionamento: qual a dificuldade dos estudantes em vincular os conceitos, as teorias e as ferramentas matemáticas na análise e solução de 
problemas de engenharia? Ou melhor, como pode-se proporcionar ao estudante de engenharia, o melhor aproveitamento da prévia Educação Matemática? Nas disciplinas-meio do curso de Engenharia são apresentadas situações-problemas que requerem a leitura e a interpretação, a adequação de leis e postulados e, posteriormente, uma formulação matemática e explicação desse fenômeno. Requer-se do estudante, muitas vezes, a solução analítica de um determinado problema, cuja modelagem matemática resulta numa equação diferencial ordinária ou mesmo numa equação diferencial parcial, ou ainda, num sistema de equações diferencias (TEDESCHI, 2006). Nestas situações, para se ter uma solução analítica, são consideradas mais algumas simplificações (de acordo com o fenômeno e com a situação específica). Algumas destas possíveis soluções, somente são possíveis, por meio do uso de transformação de variáveis, da adimensionalização das equações, do emprego de séries de Fourier, de Transformada de Laplace, etc., técnicas estas que os estudantes teoricamente já tiveram contato nas disciplinas anteriores.

Além da solução analítica exata ou mesmo aproximada, outras vezes, pode-se recorrer a procedimentos numéricos computacionais, que em geral, são mais facilmente "lembrados" pelos estudantes, embora, ainda necessitem de uma revisão direcionada a aplicação ou fenômeno em questão.

No entanto, a experiência tem mostrado que tais ferramentas ou técnicas (analíticas ou numéricas) já vistas, ou mesmo aprendidas anteriormente, necessitam de ser revistas novamente. Os professores de Engenharia, não têm o domínio do jargão da matemática (como um todo), nem a formação específica, no entanto, necessitam de fazer uma "revisão" destes conceitos, com viés mais aplicado. Desta forma, o docente acaba por dedicar um tempo (inicialmente não previsto em sua programação ou plano de ensino/aula) para esta atividade. Pois, percebe-se que o estudante, sozinho, sem o professor, não consegue "avançar" no assunto em questão.

Embora esta problemática no âmbito do ensino e na aprendizagem de Cálculo e demais disciplinas da matemática seja amplamente discutida, soluções e/ou recomendações não são ainda claras, objetivas e consensuais.

Muitas vezes, os trabalhos desenvolvidos se fundamentam na ideia de que "os alunos estão ingressando na universidade cada vez mais despreparados" (MALTA, 2004). Ou ainda, partem do princípio de que as dificuldades em relação ao ensino e a aprendizagem devem ser enfrentadas e corrigidas no ensino superior (ALMEIDA, FATORI e SOUZA, 2007).

Conforme destacam Almeida, Fatori e Souza (2007), embora a modelagem matemática: "faça parte de programas curriculares de vários cursos de Engenharia nas disciplinas específicas e básicas, pouco se alterou na prática em sala de aula. De fato, o que mudou nas escolas e universidades foi apenas a estrutura física (mobiliário moderno, computadores, internet, etc.). Mas, a estrutura educacional permanece a mesma com currículo pautado em muitas disciplinas, tempo insuficiente para que sejam aprofundadas e cada uma dessas disciplinas sob responsabilidade de um professor, dificultando que mudanças significativas se produzam na formação dos estudantes. Não se pode afrontar a evidência que boa parte dos professores procura meios eficazes para que os estudantes aprendam. Os recursos didáticos variam de acordo com o assunto que se pretende tratar, empregando um método que se julga adequado para promover aprendizagem. Contudo, nesta estrutura, sem que os professores de disciplinas afins se reúnam para organizar uma proposta eficiente e cada professor ensinando o conteúdo sob sua concepção, não contribui para que os estudantes percebam a realidade, se interessem pelas questões do meio, expressem propostas, apresentem uma nova criação." 
Esta situação ora analisada está relacionada também ao advento das Diretrizes Curriculares Nacionais - DCNs (Resolução CNE/CES 11/2002), que estabeleceram o fim dos currículos mínimos obrigatórios e, por outro lado, incorporaram a flexibilização curricular. As DCNs trazem, em síntese, a intenção de se mudar a base filosófica dos cursos de Engenharia, enfocando-os na lógica da competência e na busca de uma abordagem pedagógica "centrada no aluno com ênfase na síntese e na transdisciplinaridade"(TONINI e PINTO, 2008).

Tonini e Pinto (2008) ressaltam que o papel da flexibilização curricular: "Através da flexibilização, o currículo formal deixa de ter preponderância sobre um currículo estruturado por meio de um projeto pedagógico do curso (PPC) bem delineado e constantemente reavaliado, cujo objetivo principal será orientar a vida acadêmica do futuro engenheiro, levando em conta a diversidade do público a que se destina, seja na academia, seja no mundo do trabalho."

Tonini e Pinto (2008) destacam ainda o papel da flexibilização curricular: "o processo de flexibilização curricular não pode ser entendido como uma mera modificação ou acréscimo de atividades complementares na estrutura curricular. Ele exige que as mudanças na estrutura do currículo e na prática pedagógica estejam em consonância com os princípios e com as diretrizes do projeto político-pedagógico, na perspectiva de um ensino de graduação de qualidade."

Biembengut (1998) evidencia que: "ao fazermos uso da modelagem como método de ensino, buscamos conceber uma matemática que propicie ao estudante a possibilidade de se inteirar com questões que vai lidar futuramente e especialmente, promover a aproximação entre as diversas disciplinas do curso. Embora não se subestime a importância da modelagem matemática como método de ensino e de aprendizagem, alguns aspectos devem ser verificados para não sublinhar com demasiada ênfase, se esquecendo de limitações que a estrutura educacional produz tanto para o professor quanto para os estudantes. Por exemplo: o número de disciplinas por semestre, aliado a não continuidade de alguns estudantes na mesma turma e de diferentes professores (da mesma área), dificulta realizar um trabalho de pesquisa, conjuntamente, a longo prazo; ausência de interação entre os professores das disciplinas básicas (Álgebral Matemática, Física, Química) e os das demais disciplinas do curso, impede o professor de conhecer as necessidades especificas de cada área, o que contribui para a repetição de tópicos elou negligência de alguns essenciais. Na dificuldade momentânea de transformar a estrutura educacional vigente, a proposta é convocar professores pesquisadores a buscar por novos caminhos, processos e métodos necessários para adquirir conhecimentos necessários para fazer mudança na estrutura educacional para trazer necessário e suficiente conhecimento aos professores e estudantes em qualquer etapa de escolaridade."

Buriasco (1999) em seu estudo sobre avaliação em matemática diz que "uma das atuais grandes tendências da Educação Matemática é a Resolução de Problemas, assim chamada porque considera que o estudo da Matemática é resolver problemas".

Na Resolução de Problemas, segundo Buriasco (1999), os alunos devem desenvolver alguma estratégia para resolver o problema proposto e o ponto de partida do trabalho em sala de aula passa a ser o problema e não a definição.

Levando-se em consideração o que ora foi discutido, é desejável que o ambiente de sala de aula possa oportunizar ao estudante se colocar num contexto em que seu compromisso com a aula das disciplinas da área de matemática "transpasse o desenvolvimento fragmentado, mecânico e reprodutor de habilidades, para que possa tornar- 
se o condutor do próprio processo de aprendizagem, por meio de tarefas que suscitem habilidades que abrangem níveis de conexão e de reflexão (BURIASCO, 1999).

\section{RESULTADOS E DISCUSSÃO}

Os levantamentos foram realizados por meio de coleta de dados, valendo-se de entrevistas individuais junto a professores e estudantes, e também, por meio eletrônico, através do site http://www.survio.com/br/, somente para os discentes. Ao total, foram entrevistados cerca de 100 alunos de diversos cursos da área de Engenharia da Universidade Federal de Viçosa, ao longo do primeiro semestre de 2016.

O formulário elaborado constituiu-se de questões, cujas respostas foram baseadas no formato Likert, quanto à validade das alternativas de repostas. Tal instrumento de medida, foi adotado de modo a tentar mensurar a realidade sobre o objeto em estudo, permitindo conclusões apropriadas e confiáveis (MATTAR, 1999; KROSNICK e BERENT, 1993; COTE e BUCKLEY, 1988).

$\mathrm{Na}$ investigação realizada junto aos estudantes dos cursos de Engenharia de diversas modalidades na UFV, os dados coletados mostram que os estudantes entendem que a Matemática e as matérias relacionadas à Matemática são importantes para seu curso de graduação (Figuras 1 a e 1 b).

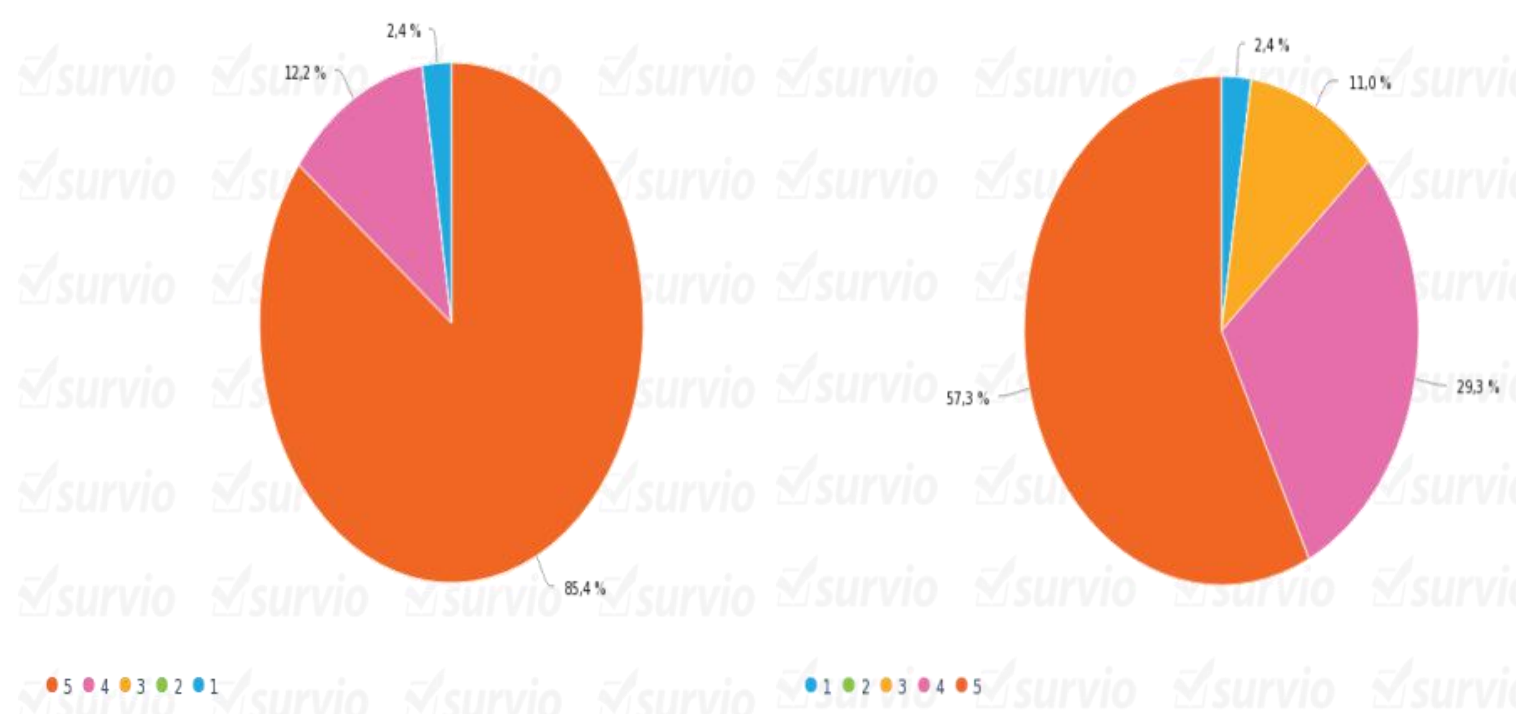

a) Importância da Matemática para o

b) Importância dos conteúdos relacionados curso. à Matemática para a carreira profissional.

Figura 1 - Importância da Matemática.

A Figura 1 a apresenta o resultado referente à percepção por parte do estudante do grau de importância das disciplinas da área de Cálculo para o seu curso. Onde se considera a escala Likert de 5 pontos, sendo 1 para pouco importante a 5 , correspondendo a muito importante. Portanto, os resultados indicam que mais der $85 \%$ dos entrevistados consideram muito importante para seu curso, as disciplinas de Cálculo e correlatas.

A Figura $1 \mathrm{~b}$, por sua vez, aborda o mesmo questionamento, porém direcionado para a formação profissional do entrevistado. Ou seja, diferentemente, do item anterior, a Figura 1 
mostra que quase $60 \%$ dos entrevistados, percebem a significância do Cálculo para sua carreira profissional.

As dificuldades em Matemática encontradas pelos alunos ao ingressarem no Ensino Superior, tornam-se cada vez mais frequentes. No decorrer dos semestres constata-se que as dificuldades estão aumentando gradativamente nos cursos que utilizam as disciplinas de Matemática no primeiro semestre, conforme ressalta Gonçalves (2007). O baixo rendimento permanece e isso pode ser verificado pelo alto índice de reprovação e evasão nessas disciplinas.

Considera-se aqui o conceito de evasão apresentado por Teles (1995), compreende evasão como toda e qualquer forma de saída do aluno do curso de graduação onde ingressou inicialmente. Esse conceito compreende as desistências, as mudanças de curso e/ou unidade, o abandono, a transferência e o jubilamento (desligamento compulsório por decurso do tempo máximo de graduação ou reprovações acima do limite máximo permitido).

Os alunos entrevistados responderam que gostam ou apresentam interesse pela Matemática, e suas matérias afins, conforme destacado pela Figura 2 a. Por outro lado cerca de $1 / 4$ dos respondentes disseram que têm dificuldades com a Matemática (Figura 2 b).

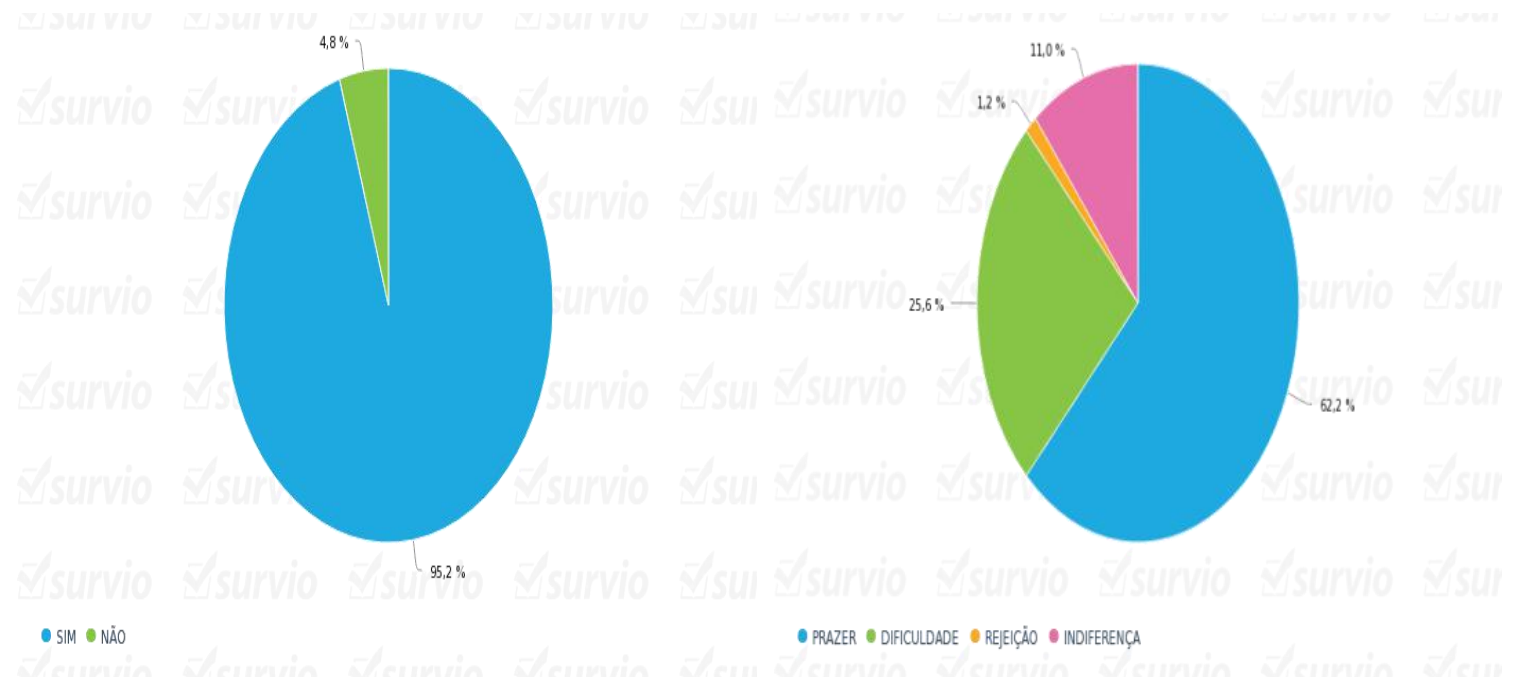

a) Interesse pela Matemática.

b) Reação a Matemática.

Figura 2 - Interesse e reação a matemática e disciplinas afins.

Conforme se verifica pela Figura 2 a, mais de 95\% dos estudantes "manifestam" interesse ("gosto") pela Matemática, o que nos causa certa estranheza, visto que a Figura 2 b atesta que muitos estudantes apresentam dificuldade em relação à mesma (o que representa, mais de $1 / 4$ dos entrevistados), enquanto que $11 \%$ dos alunos responderam que se sentem indiferentes à Matemática

As dificuldades de aprendizagem em Matemática levantadas pelos estudantes podem se manifestar nos seguintes aspectos, conforme destaca Sanchez (2004):

1. Dificuldades em relação ao desenvolvimento cognitivo e à construção da experiência matemática;

2. Dificuldades na resolução de problemas;

3. Dificuldades quanto às crenças, às atitudes, às expectativas e aos fatores emocionais acerca da matemática;

4. Dificuldades relativas à própria complexidade da matemática; 
5. Dificuldades originadas no ensino inadequado ou insuficiente.

De acordo com Malta (2004), no ensino superior as disciplinas dos cursos iniciais da área de ciências exatas, onde há elevado número de reprovações, convergem todas as preocupações dos iniciantes. Principalmente sobre o ensino de Matemática como um todo, há inúmeras pesquisas em desenvolvimento e outras já estudadas que focam vários temas para o ensino da disciplina como: utilização de Modelagem Matemática, o uso de TICs, entre outras. Tais tendências têm objetivo de tornar o ensino de Cálculo mais atrativo e melhorar o aproveitamento dos conteúdos.

Diante dos problemas na aprendizagem do Cálculo, os usos de TIC's podem contribuir para a compreensão, por exemplo, na visualização de gráficos. O uso de recursos tecnológicos quando utilizados de maneira correta se tornam auxiliares facilitando a aprendizagem dos conteúdos matemáticos, motivando os alunos a estruturar seu próprio conhecimento, com ajuda das ferramentas tecnológicas.

"Em particular, no que diz respeito ao trabalho com o Cálculo, ele (o computador) é uma ferramenta extremamente útil para propiciar a formulação de inúmeros questionamentos, reflexões e análises que fazem com que a sala de aula se torne visivelmente um ambiente onde relações podem ser estabelecidas, possibilitando articulações diversas e, portanto a construção do conhecimento. ” (BARUFI, 1999).

Sabemos que as dificuldades dos alunos nos conteúdos básicos para desenvolver estratégias de resoluções de problemas na Matemática, são trazidas do ensino básico. Além disso, dificilmente os conteúdos pré calculo são estudados no ensino médio, assim o primeiro contato com conteúdos de Cálculo se dá nos primeiros semestres do ensino superior. Portanto ao começarem estudar Cálculo, os alunos não percebem a importância destas disciplinas em seu curso e as reprovações, em geral, são atribuídas às dificuldades dos conteúdos, mas na verdade muitos alunos não se interessam na procura de conhecimentos que auxiliem na compreensão nas aplicações dos conteúdos e dessa forma se limitam ao que aprendem em sala de aula.

A metodologia usada pelos professores também tem interferido na aprendizagem dos alunos, "pois muitos deles sentem dificuldades ao se depararem com uma linguagem muito direta e com um ritmo acelerado para cumprir a carga horária" (BEZERRA, 2013). Sendo assim a metodologia usada por muitos professores contribui para o fracasso de muitos alunos, por não dar atenção às dificuldades dos alunos, causando insegurança e angústia, pois eles encontram um alto grau de abstração nos conteúdos e metodologias pouco ajuda na compreensão das disciplinas.

Os resultados do levantamento mostram que os alunos se reconhecem como o maior responsável pelo fracasso acadêmico na área de matemática e cerca de $35 \%$ dos entrevistados, atribuem esta responsabilidade aos docentes e a instituição, conforme se observa pelo gráfico da Figura 3 a. Cabe-se destacar, portanto que o professor deve estar sempre atento em dar aos alunos as ferramentas metodológicas, tecnológicas e inovadoras necessárias para aperfeiçoar o processo de aprendizagem. Dessa forma, esses alunos estarão mais bem preparados e, diante de um possível fracasso acadêmico, terão a consciência de não culparem os docentes, devido a todas as ações realizadas previamente.

No entanto, este auto reconhecimento ou mesmo consciência do grau de responsabilização pelos seus atos durante a vida acadêmica não é algo tão imediato. $\mathrm{O}$ que novamente, contrapõe com os resultados apresentados na Figura 3 a. 


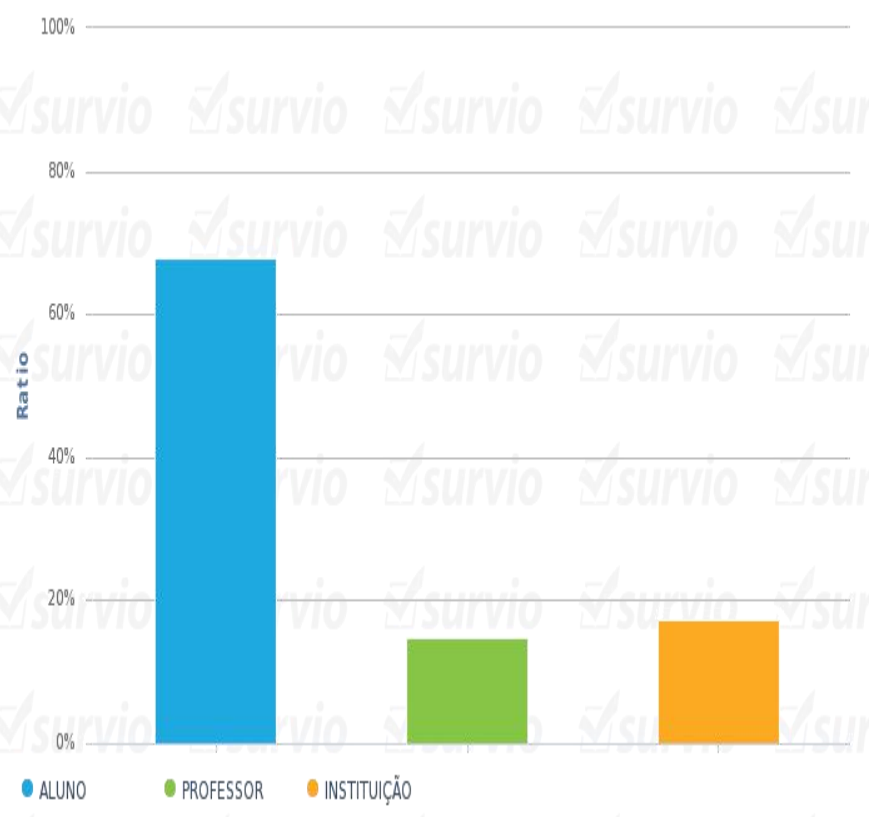

a) Responsabilidade pelo fracasso acadêmico.

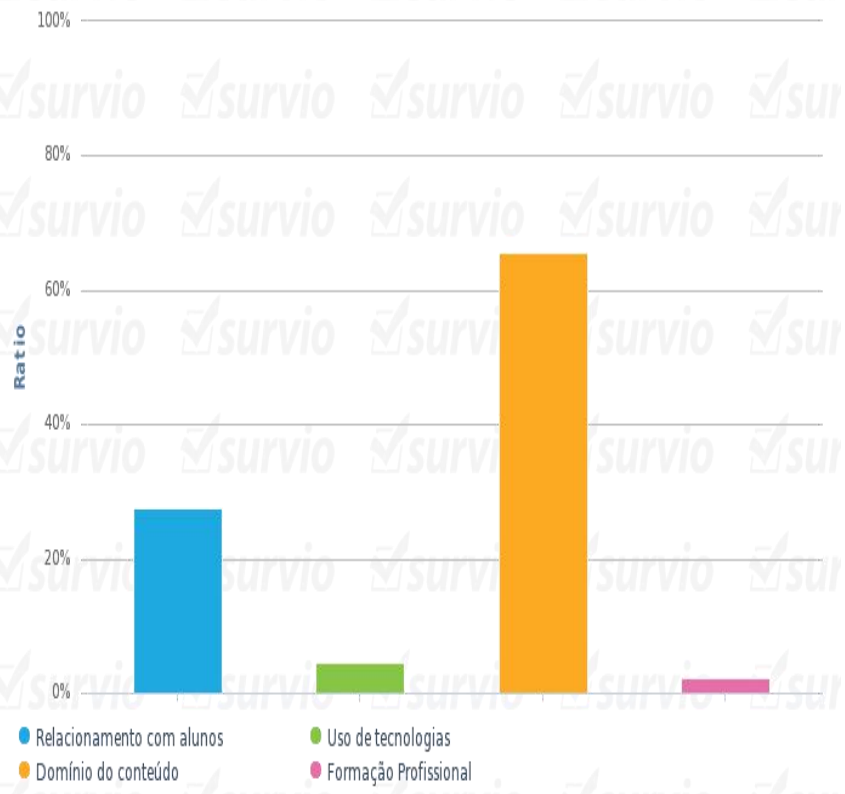

b) Fator mais importante em relação ao professor de Matemática.

Figura 3 - Responsabilidade no processo de ensino-aprendizagem em Matemática.

Ainda sobre a contribuição do trabalho docente no processo de ensino-aprendizagem em matemática, os estudantes indicam que o domínio do tema pelo docente é o fator preponderante (com $65 \%$ das respostas). Os entrevistados identificam que o relacionamento docente-aluno, é o segundo fator mais significativo para sucesso no processo ensinoaprendizagem em matemática. Já o uso de tecnologias de informação e comunicação, como mostra a Figura 3 b, pouco foi lembrado pelos entrevistados.

Tais resultados atestam a necessidade de avaliação da formação e atualização do docente, que de maneira geral, não tem conhecimentos específicos de didática, bem como a 
identificação de novas Tecnologias Digitais de Informação e Comunicação na era da Web 2.0, de modo aproximar o estudante da área da matemática.

Os resultados apresentados na Figura 3b mostram ainda que a titulação do docente (se doutor, mestre, especialista ou graduado) pouco importa no processo de ensino. Ou seja, na visão do estudante, a titulação do docente não contribui para a qualificação do mesmo, com relação ao domínio dos conceitos relacionados à didática e muito menos com o desempenho satisfatório ou não do estudante, conforme discussão mais adiante.

Conforme Correia e Pile (2004) e Alarcão (2000), há vários fatores que influenciam na adaptação, no percurso e no desempenho dos alunos: aspectos sócio-econômicos, relações sociais, fatores psicológicos, dimensão pedagógico - didática e aspectos relacionados com a organização curricular.

Libanêo appud Davidov (1978), diz que um professor não basta dominar o conteúdo, é preciso que saiba mais três coisas: "a) qual é o processo de pesquisa pelo qual se chegou a esse conteúdo, ou seja, a epistemologia da ciência que ensina; b) por quais métodos e procedimentos ensinará seus alunos a se apropriarem dos conteúdos da ciência ensinada e, especialmente, das ações mentais ligadas a esses conteúdos; c) quais são as características individuais e socioculturais dos alunos e os motivos que os impulsionam, de modo, a saber, ligar os conteúdos com esses motivos."

Neste levantamento, observa-se que a totalidade dos entrevistados respondeu que uma boa prática pedagógica de um professor de matemática pode mudar a opinião do aluno quanto à disciplina (Figura 4a). Mas os mesmos entrevistados consideram capazes de ter êxito mesmo com um professor que não tenha uma boa prática pedagógica (Figura 4 b).

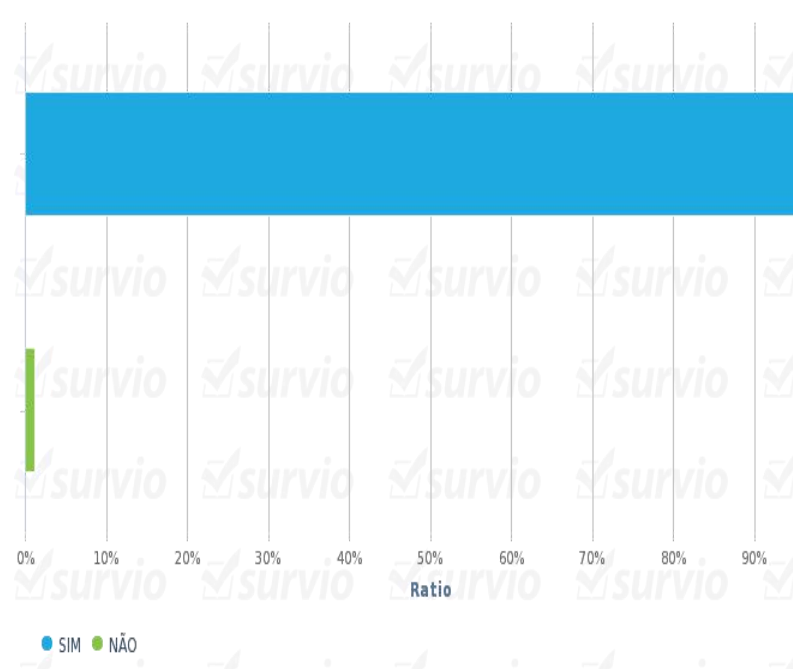

a) Uma boa prática pedagógica pode mudar opinião do aluno.

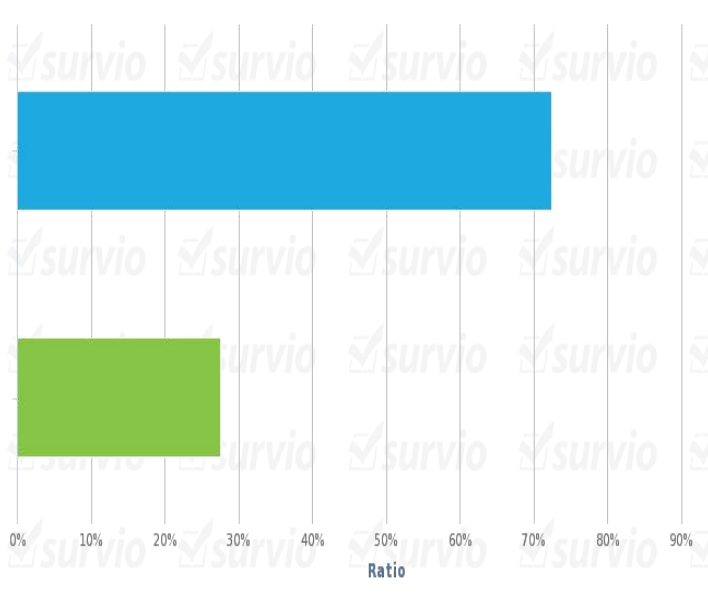

- SIM - NÃo

b) Sucesso mesmo com uma "má prática pedagógica”.

Figura 4 - Práticas Pedagógicas.

Charlot (2005) frisa que ensinar é complexo, dinâmico, difícil de ser analisado separadamente do aprender. A profissão do professor, sendo o profissional no processo ensino-aprendizagem é muito difícil de ser estudada. Não se pode desconsiderar que as atividades do professor se dão muitas vezes dentro de uma estrutura definida, o que interfere no seu trabalho. 
Em outra questão do levantamento sobre o ensino da Matemática, nota-se uma divisão igualmente de opiniões, sendo que $1 / 3$ dos entrevistados disseram que o ensino da Matemática é insuficiente, 1/3 considera o ensino de matemática como satisfatório e o mesmo percentual consideram bom, conforme destacado na Figura 5 a. Observa-se ainda, que somente $1 \%$ considera o ensino como excelente.

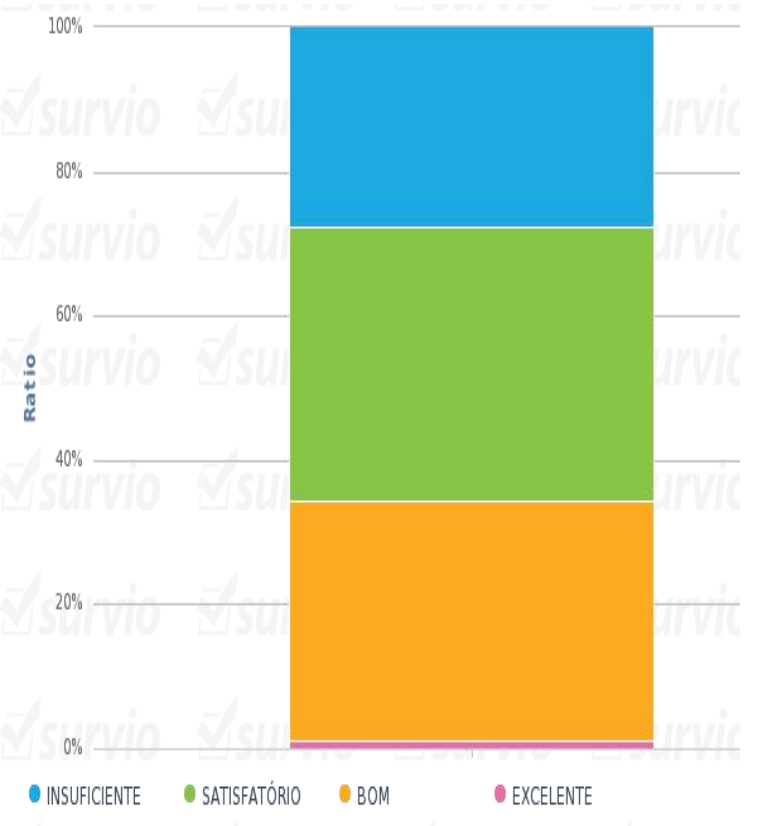

a) Ensino de Matemática no Curso superior.

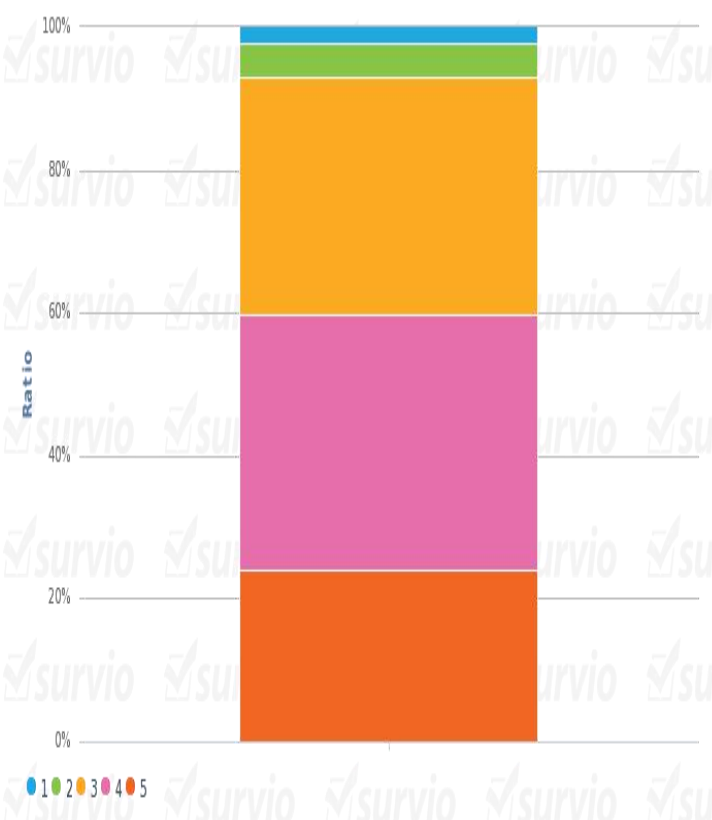

b) Responsabilidade do professor de Matemática no sucesso profissional.

Figura 5 - Ensino e responsabilidade.

Atualmente o professor tem que buscar novos elementos motivacionais para proporcionar maior entusiasmo nos alunos. No caso especifico da Matemática, essa necessidade de busca é maior, pois o aluno tem muitas dificuldades de entender e assimilar certos conceitos na sua área de conhecimento.

Quanto ao grau de responsabilidade do professor de Matemática no sucesso profissional, os alunos responderam que o professor é importante (a muito importante) no seu sucesso como profissional, conforme pode-se observar pela Figura $5 \mathrm{~b}$.

A formação pedagógica do professor tem impacto na formação do aluno e este fator pode potencializar o fracasso acadêmico, visto que o professor não utiliza de recursos necessários para ajudar essa aprendizagem. Dessa forma os professores deveriam ser reflexivos sobre sua atuação pedagógica, reflexão essa que auxiliaria na condução de sua metodologia.

A formação do professor deveria ser preponderante para minimizar o déficit de aprendizagem trazido pelos alunos. Professores são responsáveis pelas interações sociais dos alunos e são intermediadores na construção desse saber. A produção do conhecimento não deve ser do modo tradicional, ou seja, o professor ensina e o aluno aprende. O aluno deve ter participação ativa na construção do seu conhecimento.

Para Carbonell (2002), o professor se desenvolve melhor quando exerce sua profissão com paixão e compromisso pela docência, com objetivo de estreitar as relações entre 
professor-conteúdo-aluno de forma mais educativa. Mas para que o professor se desenvolva, ele deve pensar, refletir e planejar juntos com seus alunos, buscando essa ação educativa.

O que chama atenção neste caso específico de levantamento foi em relação à última questão correspondente ao grau de domínio dos alunos a alguns temas da área da Matemática. Nesta última pergunta, os alunos responderam sobre o seu domínio sobre os seguintes temas da Matemática: Derivada, Integral, Série de Taylor, Série de Fourier, Equações Diferenciais Ordinárias, Equações Diferenciais Parciais e Métodos Numéricos, conforme apresentado na Figura 6.

Mesmo respondendo anteriormente que apresentam dificuldades nas disciplinas de Matemática, muitos alunos disseram que têm domínio de derivadas e integrais, mas na prática o que se observa, segundo os professores entrevistados, é grande dificuldade que os alunos de engenharia têm nesses conceitos fundamentais.

Nas disciplinas iniciais dos cursos de Engenharia: as disciplinas de Cálculo Integral e Diferencial I apresentam alto o índice de reprovação e evasão. Os discentes, entrevistados, encontram dificuldades quando se trata da compreensão da disciplina, isto deve ao fato de como são lecionados esses conteúdos, na sua maioria são transmitidos pelo Método Tradicional dificultando a compreensão dos conteúdos, como bem destaca Andrade (2008).

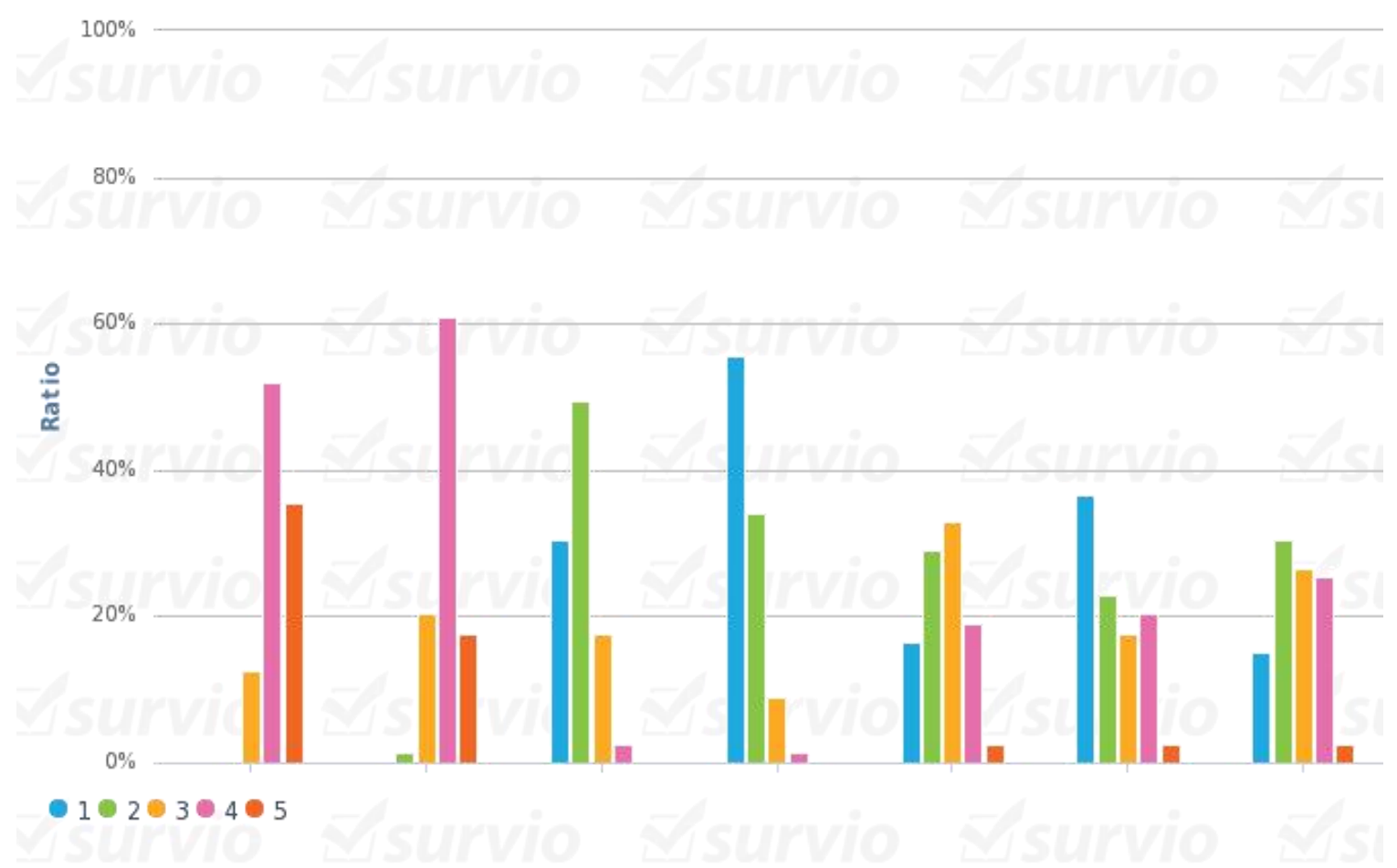

a) Domínio dos temas da Matemática

Figura 6 - Temas da área de Matemática

Para os pesquisadores, a matemática é indispensável para a comunidade da engenharia e o grande desafio é adequá-la às necessidades de uma linguagem que seja ferramenta para descrever as leis que regem as Ciências da Natureza, sem com isso distanciar das aplicações empíricas. 
Além de Cálculos, alunos da área de ciências exatas, especificamente Engenharias, precisam dominar outros temas como as Equações Diferenciais (Ordinárias e Parciais), portanto a compreensão dos conceitos básicos envolvidos nessas equações e a obtenção de suas soluções fazem parte da formação desses alunos. Porém, a falta de motivação para o estudo desses temas termina refletindo na evasão e reprovação nas disciplinas de conteúdos associados ao Cálculo, conforme apontado por Passos et al. (2007).

Nota-se no levantamento que a grande maioria dos entrevistados não domina temas da Matemática importantíssimos a um engenheiro como Série de Fourier, Transformada de Laplace, Séries de Taylor, Funções de Bessel, etc. O estudo das séries de Fourier, por exemplo, tem inúmeras aplicações nas Engenharias, na Física e na Matemática. Com ela pode-se resolver diversos problemas relacionados a área de Fenômenos de Transporte (Mecânica dos Fluidos, Transferência de Calor e Transferência de Massa).

A Transformada de Laplace, da mesma forma, é muito utilizada em Cálculo e Engenharias. É usada em sistemas que não variam no tempo, como sistemas mecânicos, osciladores harmônicos. A vantagem de estudar a Transformada de Laplace é que as integrações e derivações se tornam multiplicações e divisões o que permite resolver equações diferenciais na forma de equações polinomiais e algébricas.

Séries de Taylor é fundamentalmente usada em Cálculo Numérico e aproximações de funções, além de ser fundamental para análise de convergência de métodos interativos, estudos de máximo e mínimo e equações ordinárias.

\section{CONCLUSÃO}

O ensino da Matemática é muito importante para os cursos na área de exatas, porém vários problemas nos cursos iniciais no ensino superior ainda persistem. $\mathrm{O}$ alto índice de reprovação nas disciplinas, isso devido à deficiência procedente de sua formação anterior, afetando seu desempenho nos anos seguintes. Professores que não possuem percepção do nível de aprendizagem dos iniciantes. Faz-se necessário mudar esse cenário, reduzir as reprovações, aumentar o diálogo, corrigir, reformar o processo de avaliação. A educação tem como princípio promover transformações na formação dos alunos inovadores e dinâmicos, capazes de intervir em seu meio para uma "consciência global e sistêmica" (PASSOS et al 2007). As disciplinas iniciais de Matemática precisam ser ordenadas de modo a capacitar os iniciantes no aperfeiçoamento do raciocínio lógico e associarem os conceitos matemáticos a sua vivência profissional.

Nesse sentido, recomenda-se a associação de novas tecnologias educacionais, como o uso de TIC's e da Web 2.0, bem como um processo de reflexão por parte dos professores sobre a sua prática docente.

Espera-se que esse trabalho seja início da ampliação do debate na Universidade, contribuindo com a dinamização do processo de ensino, sua relação com o conhecimento e com a construção de aprendizagens; além de implementar iniciativas e experiências didáticas e metodológicas que visem à melhoria do processo de ensino e aprendizagem no ensino superior. 


\section{AGRADECIMENTOS}

Os autores agradecem o apoio institucional da Fundação de Apoio a Pesquisa do Estado de Minas Gerais - FAPEMIG, bem como da UFVCredi pelo aporte de bolsa de projeto de pesquisa em ensino, e, por fim, da FUNARBE, e da Universidade Federal de Viçosa - UFV, pelo apoio logístico.

\section{REFERÊNCIAS}

ALARCÃO, I. Para uma conceptualização dos fenómenos do insucesso/sucesso escolares no ensino superior. In J. Didáctica da Educação Visual. Lisboa: Universidade Aberta, 1995.Tavares, (Org.), Ensino Superior, (In)sucesso Académico (p. 11 a 23). Porto: Porto Editora, 2000.

ALMEIDA, C.S. Dificuldades de aprendizagem em matemática e a percepção dos professores em relação a fatores associados ao insucesso nesta área. 2006. $13 \mathrm{f}$. Monografia (Graduação) - Universidade Católica de Brasília, Brasília, 2006.

ALMEIDA, L.M.W., FATORI, L.H., SOUZA, L.G.S. Ensino de Cálculo: uma abordagem usando Modelagem Matemática. RCT. v. 10, n. 16 (2007).

ANDRADE, A.A. A importância do cálculo diferencial e integral e suas aplicações no ensino da química no ensino superior. Monografia (Licenciatura em Matemática) Instituto Federal de Educação, Ciência e Tecnologia do Maranhão. São Luís. 2008.

BARROS, R.M.; MELONI, L.G.P. O processo de ensino e aprendizagem de cálculo diferencial e integral por meio de metáforas e recursos multimídia. Anais do XXXIV Congresso Brasileiro de Ensino de Engenharia- COBENGE, Passo Fundo, 2006.

BARUFI, M.C.B.A Construção/negociação de significado no curso universitário inicial de Cálculo Diferencial e Integral. 1999. 195f. Tese (Doutorado em Educação) . Universidade de São Paulo. São Paulo.

BEZERRA, A.S.V. Que razões levamos alunos de graduação a um fracasso generalizado nas disciplinas de Cálculo Diferencial e Integral? 2013. 108f. Tese de Conclusão de Curso (Graduação em Matemática). Universidade Estadual da Paraíba. Campina Grande.

BIEMBENGUT, M. S. Qualidade de ensino de matemática na engenharia: uma proposta metodológica e curricular. Florianópolis: UFSC, 1997. Tese de Doutorado, Curso de Pós-Graduação em Engenharia de Produção e Sistemas, 1997.

BURIASCO, R.L.C. de. Avaliação em matemática: um estudo das respostas de alunos e professores. Marília, SP. Tese (Doutorado) - Universidade Estadual Paulista, Campus de Marília, 1999.

CARBONELL, J. A aventura de inovar: a mudança na escola. 2. ed. Tradução Fátima. Murad. Porto Alegre: Artmed, 2002.

CHARLOT, B. Relação com o saber, Formação de Professores e Globalização: questões para a educação hoje. $1^{\mathrm{a}} \mathrm{ed}$. Porto Alegre: ARTMED, 2005.

CORREIA, T.;Gonçalves.I; Pile, M. (2004). Insucesso académico no IST. Disponível em $<$ http://gep.ist.utl.pt/files/estudos/2004/Ins_Acad_IST_vfinal.pdf $>$. Acessado em 07 de 
julho de 2016.

COTE, J. A. e BUCKLEY, M.R. Measurement error and theory testing in consumer research: an illustration of the importance of construct validation. Journal Consumer Research. n. 14, p. 579-582, 1988.

DAVYDOV, V. Tipos de generalización de la enseñanza. Havana: Editorial Pueblo y educación, 1978.

GONÇALVES, C.F. Dificuldades em matemática ao ingressar no ensino superior, 2007, 74f. Trabalho de conclusão de curso apresentado à banca examinadora do curso de Licenciatura em Matemática.Universitário La Salle. Canoas.

KROSNICK, J. A. e BERENT, M. K. Comparisons of party identification and policy preferences: the impact of survey question format. American Journal of Political Science. n. 37, v. 3, p. 941-964, 1993.

LIBÂNEO, J.C. Didática. São Paulo: Cortez, 1994.

LIMA, I.G.; SAUER, L.Z.; SOARES, E. M. S. Discutindo alternativas para ambientes de aprendizagem de matemática para cursos de Engenharia. In:World Congress on Engineering and Technology Education, 2004, Guarujá

MALTA, I. Linguagem, leitura e matemática in CURY, H. N. Disciplinas matemáticas em cursos superiores: reflexões, relatos, propostas. Porto Alegre: EDIPUCRS, 2004. p.4162.

MARIN, D. Professores de matemática que usam a tecnologia de informação e comunicação no ensino superior. São Paulo, 2009.

MATTAR, F. N. Pesquisa de Marketing. 5. ed. São Paulo: Editora Atlas, 1999.

MORAES, R. L.; VALENTE, P. S. Fundamentos de matemática: uma análise das dificuldades apresentadas pelos integrantes nos cursos de engenharia da Universidade Federal do Pará em 2014. Revista Eletrônica Engenharia Viva (2016) 17-29.

PASSOS, F.G.; DUARTE, F.R.; LEITE, A.A.M; PEREIRA, P.J.; LEITE, T.N.; DONZELI, V.P. Análise dos índices de reprovações nas disciplinas Cálculo I e Geometria Análitica nos cursos de Engenharia da UNIVASF. In. CONGRESSO BRASILEIRO DE EDUCAÇÃO EM ENGENHARIA, 2E05-1-2E05-15, 2007, Curitiba/PR. Anais do XXXV Congresso Brasileiro de Educação em Engenharia. 2007, Curitiba/PR, CDROM.

PILOTTI, M.; CUNHA, G.F.; PARMEGIANI, R. Reflexões sobre a disciplina de matemática fundamental e o aprendizado de cálculo em cursos de engenharia. Anais do XLII Congresso Brasileiro de Ensino de Engenharia - COBENGE 2014, Juiz de Fora.

PINHEIRO, N. A. M. e MORETTI ,M. T. Conhecimento matemático reflexivo no ensino de cálculo diferencial e integral: uma contribuição para as discussões sobre ciência,tecnologia e sociedade. Anais do II SIPEM - simpósio Internacional de pesquisa e Educação matemática. Santos, 2003.

QUARTIERI M, T.; BORRAGINI, E. F.; DICK, A. P. Superação de dificuldades no início dos cursos de engenharia: introdução ao estudo de física e matemática - Anais do XL Congresso Brasileiro de Ensino de Engenharia - COBENGE 2012, Belém.

SANCHEZ, J.N.G. Dificuldades de Aprendizagem e Intervenção Psicopedagógica. Porto Alegre: Artmed. 2004.

TELES, A.R.T.F. O estudo da evasão como um dos elementos de subsídio às reformas curriculares. Anais do XIII Congresso Brasileiro de Ensino de Engenharia - 
COBENGE 95, Recife.

TEDESCHI, L.O. Review assessment of the adequacy of mathematical models. Agricultural Systems, n.89, p.225-247, 2006.

TONINI, A,M., PINTO, D.P., A flexibilização curricular e a Engenharia. Educ. Tecnol., Belo Horizonte, v. 13, n. 2, p. 04-08, maio./ago. 2008.

TREVISAN, A.L., MENDES, M.T., Possibilidades para matematizar em aulas de

Cálculo. R. B. E. C. T., vol 6, núm. 1, jan-abr. 2013.

\title{
MATHEMATICS IN ENGINEERING EDUCATION
}

\author{
G. L. FIRMINO, A.M. O. SIQUEIRA ${ }^{1}$ \\ ${ }^{1}$ Universidade Federal de Viçosa - Departamento de Química - Programa de Pós-Graduação \\ em Engenharia Química - Viçosa - MG \\ E-mail: antonio.siqueira@ufv.br
}

\begin{abstract}
The difficulty in learning in Mathematics has been the object of researches, meetings, lectures, aiming to discover the origins of problems in teaching / learning, this work aimed to identify the main difficulties faced by students of Engineering courses when solving problems, and to investigate the minimum mathematical concepts for the satisfactory resolution of problems in discipline-middle of Engineering courses. The surveys were conducted through interviews and data collection. It is noted that the difficulties in mathematics encountered by students in the beginning classes at Higher Education, become more frequent and in the face of problems in the learning of Calculus and related courses, the uses of ICT (information and communications technology) can contribute to the improvement of the teaching-learning process. The traditional methodologies adopted by many teachers contribute to the failure of many students, not paying attention to their difficulties, causing insecurity and anguish, because they find a high degree of abstraction in the contents. In this sense, it is recommended the association of new educational technologies, such as the use of ICTs and Web 2.0, as well as a reflection process on the part of teachers about their teaching practice.
\end{abstract}

KEYWORDS: Teaching and learning; Mathematics;Calculus; Engineering Education . 